\title{
On Oncogenes and Tumor Suppressor Genes in the Mammary Gland
}

\author{
Rushika M. Perera and Nabeel Bardeesy \\ Harvard Medical School, Center for Cancer Research, Boston, Massachusetts 02114 \\ Correspondence: Bardeesy.Nabeel@MGH.harvard.edu
}

$\mathrm{B}_{8}^{\mathrm{r}}$ reast cancer in humans is associated with genetic alterations of a number of oncogenes (ErbB2, MYC, PIK3CA) and tumor suppressors (TP53, BRCA1/2, RB1, PTEN), as outlined by Lee and Muller. The use of genetically engineered mouse models harboring deletions or mutations in these genes has provided insight into how such alterations drive tumor initiation, progression, and metastasis, and how they influence responses to anticancer agents. Beyond these well-characterized alterations, there has been a recent explosion in new information regarding the molecular pathogenesis of breast cancer, and therefore a need to define the functional roles of newly described potential breast cancer genes. For example, whole-genome sequencing has identified a large number of genes with recurrent sequence alterations in human breast cancer specimens (Wood et al. 2007). Moreover, gene copy number analyses have identified multiple regions of chromosomal gain or loss (Chin et al. 2006). Finally, microRNAs and other types of noncoding RNA have recently emerged as important modulators of cancer phenotypes (Ventura and Jacks 2009). Despite, this new information about cancer-associated molecular alterations, the full characterization of their impact on breast cancer biology in vivo remains incomplete. Therefore, a major current challenge is to functionally annotate these emerging groups of candidate breast cancer tumor suppressors/oncogenes.
The generation of additional mouse models with engineered mutations or transgenic expression of new candidate genes will provide important information validating their role in cancer and elucidating their specific biological activities. However, it is important to point out that the existing mouse models do not recapitulate the estrogen receptor (ER)-positive histological subtype of breast cancer, which is an important subset in humans. Thus, current transgenic approaches do not provide a comprehensive platform for modeling the full spectrum of the human disease. An equally important issue is that the considerable time and expense of generating new engineered alleles and breeding to obtain compound mutant strains creates a bottleneck in fully annotating the breast cancer genome. Gain- and loss-of-function experiments in cancer cell lines and in immortalized breast epithelial cells (Weaver et al. 1995) can in many cases determine the roles of novel regulators of cellular transformation. However, factors contributing to cancer pathogenesis through such processes as control of cellular senescence, reprogramming of the cellular differentiation state, and interactions with the microenvironment may not be readily studied in such systems. Although xenografts of human cancer cell lines may be helpful in some cases, the functions of other cancer-relevant factors may be best uncovered by the genetic manipulation of primary cells and their subsequent growth as orthotopic

Editors: Mina J. Bissell, Kornelia Polyak, and Jeffrey M. Rosen

Additional Perspectives on The Mammary Gland as an Experimental Model available at www.cshperspectives.org

Copyright (C) 2012 Cold Spring Harbor Laboratory Press; all rights reserved; doi: 10.1101/cshperspect.a013466

Cite this article as Cold Spring Harb Perspect Biol 2012;4:a013466 
implants (Heyer et al. 2010). By using isogenic cells, it is possible to the study tumor formation of such implants in the context of wild-type mice with a fully intact immune system, thereby fully recapitulating the microenvironment of spontaneous tumors. Breast progenitor/stem cells provide a valuable system in this regard, although the selection of other types of breast epithelial cells would likely influence the ensuing tumor phenotype and have utility in studying histological subtypes of breast cancer.

An additional important question in annotating the breast cancer genome is whether a genetic lesion contributes to the maintenance of established tumors-rather than just to tumor initiation - and therefore points to a pathway whose deregulation represents a potential drug target. Lee and Muller (2011) refer to work with doxycline-inducible transgenics indicating that tumors induced by ErbB2 remain dependent on this factor for tumor maintenance. The generation of additional inducible overexpression systems and the use of inducible short hairpin RNA (shRNA) in the transplantable models discussed above will be important for defining additional factors required for tumor maintenance. The molecular and cellular alterations resulting from switching off a candidate oncogene in vivo also provides important benchmarks with which to evaluate new drugs that are designed to target such pathways.

Noncoding RNAs represent an emerging class of cancer regulators in need of further study in vivo. Micro RNAs (miRNAs) are the most studied group of noncoding RNAs, and individual miRNAs have been shown to function as oncogenes and tumor suppressors in mouse models (Ventura and Jacks 2009). Deregulated miRNAs in breast cancer include miR-210 (Camps et al. 2008), a hypoxia-regulated miRNA that contributes to cancer growth by regulating energy metabolism. miR-335, $-126,-10 \mathrm{~b}$, and miR-31 have all been shown to regulate invasion and metastasis (Ma et al. 2007; Tavazoie et al. 2008; Valastyan et al. 2009), and let7b and miR-200 negatively regulate breast cancer stem cell self-renewal (Iliopoulos et al. 2009; Shimono et al. 2009). The functional validation of these and other classes of noncoding
RNAs in vivo is likely to yield novel observations about the molecular circuitry of breast cancer cells.

The molecular pathogenesis of metastasis is a rapidly evolving area of research, and recent efforts have helped define activators and repressors of breast cancer metastasis as well as factors that influence the site of metastatic growth. Notably, it is now apparent that metastatic lesions have marked differences in mutational profiles compared to the primary tumors. Whole-genome sequencing of paired primary and metastatic basal-cell-like breast cancer, and xenografts of the same primary tumor tissue, identified striking similarities and some interesting differences in the prevalence of genetic mutations between the samples (Ding et al. 2010). Mutations detected in the metastatic tumor were highly concordant with those detected in the tumor xenograft. However, some of these mutations were not present in the primary tumor sample. This suggests that the evolutionary pressures driving metastasis and establishment of primary xenografts may be similar, and highlight the potential usefulness of functionally assessing mutations selectively enriched in both lesions. Whether these genetic changes influence tumor cell adaptability and secondary organ site selection are key questions in ongoing efforts to understand the mechanisms governing metastatic spread. In vivo studies have also established an important causative link between metastasis and the expression of specific micro RNAs (miRNA) and identified pro- and antimetastasis regulators (Ma et al. 2007; Tavazoie et al. 2008). The mechanisms by which the expression of these miRNAs are altered and key molecular targets and cellular functions of these miRNAs require further investigation.

As new technologies provide an increasingly detailed view of mutational, gene-expression, and gene copy number profiles that define breast cancer, the potential of personalized medicine in cancer therapy becomes more attainable. The full realization of this goal will first require a broader characterization of novel candidate cancer regulators. It is clear that a multipronged approach using multiple model systems will be needed to translate genetic findings into a 
Oncogenes and Tumor Suppressor Genes

comprehensive picture of the underlying circuitry of distinct histological and genetic subsets of breast cancer.

\section{REFERENCES}

${ }^{*}$ Reference is also in this collection.

Camps C, Buffa FM, Colella S, Moore J, Sotiriou C, Sheldon H, Harris AL, Gleadle JM, Ragoussis J. 2008. hsa-miR210 is induced by hypoxia and is an independent prognostic factor in breast cancer. Clin Cancer Res 14: 1340 1348.

Chin K, DeVries S, Fridlyand J, Spellman PT, Roydasgupta R, Kuo WL, Lapuk A, Neve RM, Qian Z, Ryder T, et al. 2006. Genomic and transcriptional aberrations linked to breast cancer pathophysiologies. Cancer Cell 10: 529-541.

Ding L, Ellis MJ, Li S, Larson DE, Chen K, Wallis JW, Harris CC, McLellan MD, Fulton RS, Fulton LL, et al. 2010. Genome remodelling in a basal-like breast cancer metastasis and xenograft. Nature 464: 999-1005.

Heyer J, Kwong LN, Lowe SW, Chin L. 2010. Non-germline genetically engineered mouse models for translational cancer research. Nature Rev 10: 470-480.

Iliopoulos D, Hirsch HA, Struhl K. 2009. An epigenetic switch involving NF-кB, Lin28, Let-7 MicroRNA, and IL6 links inflammation to cell transformation. Cell 139: 693-706.
* Lee EYHP, Muller WJ. 2011. Oncogenes and tumor suppressor genes. Cold Spring Harb Perspect Biol doi: 10.1101/ cshperspect.a003236.

Ma L, Teruya-Feldstein J, Weinberg RA. 2007. Tumour invasion and metastasis initiated by microRNA-10b in breast cancer. Nature 449: 682-688.

Shimono Y, Zabala M, Cho RW, Lobo N, Dalerba P, Qian D, Diehn M, Liu H, Panula SP, Chiao E, et al. 2009. Downregulation of miRNA-200c links breast cancer stem cells with normal stem cells. Cell 138: 592-603.

Tavazoie SF, Alarcón C, Oskarsson T, Padua D, Wang Q, Bos PD, Gerald WL, Massagué J. 2008. Endogenous human microRNAs that suppress breast cancer metastasis. $\mathrm{Na}$ ture 451: 147-152.

Valastyan S, Reinhardt F, Benaich N, Calogrias D, Szász AM, Wang ZC, Brock JE, Richardson AL, Weinberg RA. 2009. A pleiotropically acting microRNA, miR-31, inhibits breast cancer metastasis. Cell 137: 1032-1046.

Ventura A, Jacks T. 2009. MicroRNAs and cancer: Short RNAs go a long way. Cell 136: 586-591.

Weaver VM, Howlett AR, Langton-Webster B, Petersen OW, Bissell MJ. 1995. The development of a functionally relevant cell culture model of progressive human breast cancer. Semin Cancer Biol 6: 175-184.

Wood LD, Parsons DW, Jones S, Lin J, Sjöblom T, Leary RJ, Shen D, Boca SM, Barber T, Ptak J, et al. 2007. The genomic landscapes of human breast and colorectal cancers. Science 318: 1108-1113. 


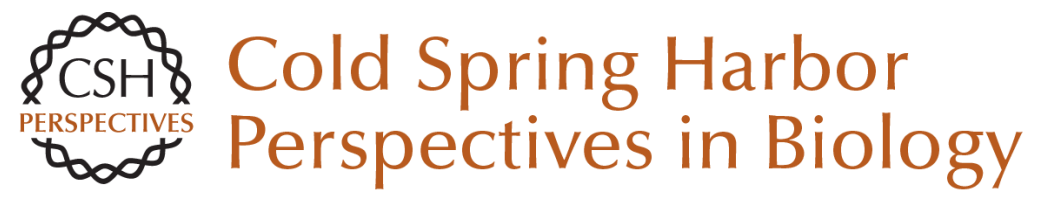

\section{On Oncogenes and Tumor Suppressor Genes in the Mammary Gland}

Rushika M. Perera and Nabeel Bardeesy

Cold Spring Harb Perspect Biol 2012; doi: 10.1101/cshperspect.a013466

Subject Collection The Mammary Gland as an Experimental Model

On the Role of the Microenvironment in Mammary Gland Development and Cancer Derek Radisky

On Using Functional Genetics to Understand Breast Cancer Biology Kornelia Polyak

On Oncogenes and Tumor Suppressor Genes in the Mammary Gland Rushika M. Perera and Nabeel Bardeesy

On Leukocytes in Mammary Development and Cancer Cyrus M. Ghajar

On Chromatin Remodeling in Mammary Gland Differentiation and Breast Tumorigenesis Kornelia Polyak

On Hormone Action in the Mammary Gland J.M. Rosen

TGF- $\beta$ Biology in Mammary Development and Breast Cancer

Harold Moses and Mary Helen Barcellos-Hoff

A Compendium of the Mouse Mammary Tumor Biologist: From the Initial Observations in the House Mouse to the Development of Genetically Engineered Mice

Robert D. Cardiff and Nicholas Kenney
On How Mammary Gland Reprogramming

Metalloproteinases Couple Form with Function Bonnie F. Sloane

On Molecular Mechanisms Guiding Embryonic Mammary Gland Development Gertraud W. Robinson

On Stem Cells in the Human Breast Mark A. LaBarge

On Murine Mammary Epithelial Stem Cells:

Discovery, Function, and Current Status Jeffrey M. Rosen

On In Vivo Imaging in Cancer David Piwnica-Worms

Choosing a Mouse Model: Experimental Biology in Context--The Utility and Limitations of Mouse Models of Breast Cancer Alexander D. Borowsky

Mammary Gland ECM Remodeling, Stiffness, and Mechanosignaling in Normal Development and Tumor Progression Pepper Schedin and Patricia J. Keely

Molecular Mechanisms Guiding Embryonic

Mammary Gland Development Pamela Cowin and John Wysolmerski

For additional articles in this collection, see http://cshperspectives.cshlp.org/cgi/collection/

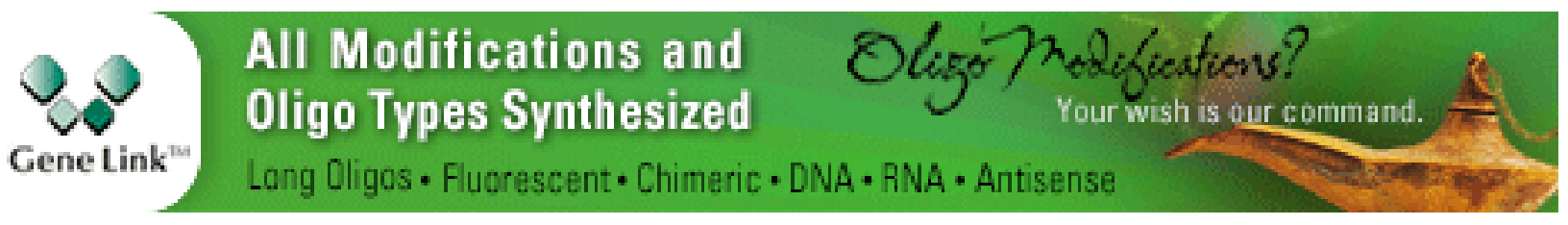


For additional articles in this collection, see http://cshperspectives.cshlp.org/cgi/collection/

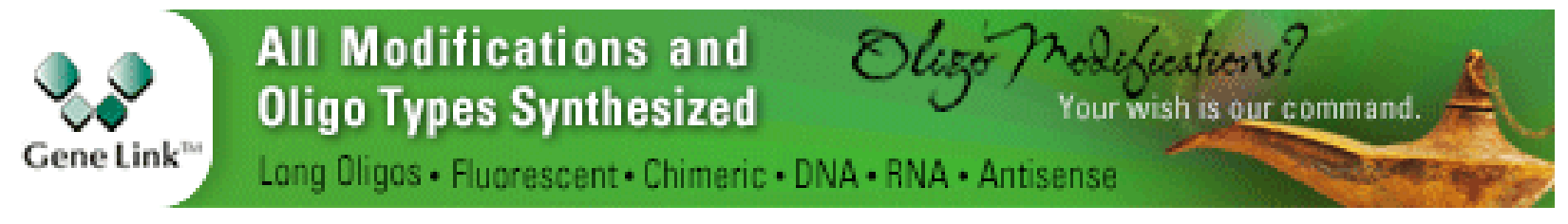

Copyright @ 2012 Cold Spring Harbor Laboratory Press; all rights reserved 